\title{
Micromilling of Metal Alloys with Focused Ion Beam-Fabricated Tools
}

\author{
D.P. Adams, M.J. Vasile*, G. Benavides, A. Campbell \\ Sandia National Laboratories, Albuquerque, NM, 87185 \\ *Louisiana Tech University, Ruston, LA, 71272
}

\begin{abstract}
:
This work combines focused ion beam sputtering and ultra-precision machining as a first step in fabricating microstructures in mietals and alloys. Specifically, $\sim 25 \mu \mathrm{m}$ diameter micro-end mills are made from cobalt M42 high-speed steel and C2 micrograin tungsten carbide tool blanks by ion beam sputtering. A $20 \mathrm{keV}$ focused gallium beam defines tool cutting edges having radii of curvature $<0.1 \mu \mathrm{m}$. Micro-end mills having 2, 4 and 5 cutting edges successfully machine small trenches in 6061-T4 aluminum, brass, 4340 steel and polymethyl methacrylate. Machined trench widths are approximately equal to the tool diameters and surface roughnesses (rms) are $\sim 150 \mathrm{~nm}$ or less. Microtools are robust and operate for more than 6 hours without fracture. Results from ultra-precision machining aluminum at feed rates as high as 50 $\mathrm{mm} /$ minute are included.
\end{abstract}

\section{Introduction:}

\section{RECEIVED} NOV 291999

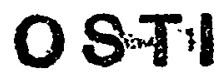

Alternative microfabrication techniques that complement or improve upon processes such as photolithography/etching, electro-discharge machining and pulsed laser drilling are being explored. ${ }^{1}$ Additional techniques are needed to enhance prototyping and production of various microcomponents and micromechanical devices. In particular, there is a desire to fabricate complex features in a diverse set of substrates and thin films. Future microdevices will be made of a variety of materials, other than those commonly used in the semiconductor industry. This includes high-strength metal alloys, ceramics, polymers and composites. Microfabrication of these materials includes creating planar and nonplanar features, such as overhangs and curved surfaces.

In this work, focused ion beam (FIB) sputtering is combined with ultra-precision machining for microfabrication. This research explores the fabrication and the performance of nicrotools designed for cutting metals. Microtools are made by FIB sputtering, because this technique affords precise control over feature size. $^{2} \mathrm{~A}$ focused ion beam is typically less than a micrometer in diameter, allowing for small features with sub$\mu \mathrm{m}$ tolerances. Commercial FIB systems provide 50 nanometer or smaller spot sizes; beam currents are typically in the nanoampere range. A substrate or workpiece in this study is positioned in two directions ( $x$ and y) or it can be rotated with respect to an ion beam, enabling nonplanar features and complex shapes to be made. The precision of focused ion beam fabrication is combined with ultra-precision milling, to determine if material can be mechanically machined at a high rate while maintaining extremely small tolerances. Several previous 


\section{DISCLAIMER}

This report was prepared as an account of work sponsored by an agency of the United States Government. Neither the United States Government nor any agency thereof, nor any of their employees, make any warranty, express or implied, or assumes any legal liability or responsibility for the accuracy, completeness, or usefulness of any information, apparatus, product, or process disclosed, or represents that its use would not infringe privately owned rights. Reference herein to any specific commercial product, process, or service by trade name, trademark, manufacturer, or otherwise does not necessarily constitute or imply its endorsement, recommendation, or favoring by the United States Government or any agency thereof. The views and opinions of authors expressed herein do not necessarily state or reflect those of the United States Government or any agency thereof. 


\section{DISCLAIMER}

Portions of this document may be illegible in electronic image products. Images are produced from the best available original document. 
studies use FIB sputtering to make small tools, including microscalpels, micro-wrenches, and nanoindenters. ${ }^{3-5}$ Application of micromilling tools concentrates on machining of polymethyl methacrylate (PMMA) but no work applying micron-size tools for machining metals or alloys has been reported. In the present work a number of micro-end mill designs are tested by milling metal alloys having different degrees of machinability.

\section{Experimental}

The focused ion beam system ${ }^{7}$ consists of a liquid metal ion source, beam deflectors, sample stage, and channelplate detector for secondary electron imaging. The ion gun produces a $20 \mathrm{keV}$ beam of $\mathrm{Ga}^{+}$ions with a near-Gaussian intensity and a full-width at half-maximum diameter of $0.4 \mu \mathrm{m}$. Currents are typically 2 nanoamperes in a Faraday cup giving a current density of $\sim 1.5 \mathrm{Amp} / \mathrm{cm}^{2}$. In practice, an operator outlines a desired shape on a sample image, and an octupole deflection system steers the beam over designated areas with sub-micron resolution. A stage positions samples with $1 \mu \mathrm{m}$ accuracy and provides for sample rotation with a minimum step size of $0.37^{\circ}$ per pulse. The $\mathrm{Ga}^{+}$source chamber is ion pumped and has a pressure of $10^{-9} \mathrm{Torr}$. The target chamber uses an oil diffusion pump to maintain a pressure of $10^{-8}$ Torr during sputtering. A small aperture separates the two chambers for efficient differential pumping.

Tool blanks are purchased from National Jet, Inc. and are made of materials commonly used for machining, including cobalt M42 high-speed steel or C2 micrograin tungsten carbide. Tool shanks are $1.02 \mathrm{~mm}$ in diameter and are brazed into a centerless ground mandrel. One end of each shank is tapered by diamond grinding and polished; this end has a $\sim 25 \mu \mathrm{m}$ diameter and is cylindrical over a length of $90 \mu \mathrm{m}$. Tools are cleaned with a dilute nitric acid mixture and coated with a thin layer of Au/Pd before FIB sputtering to minimize charging.

Two high precision milling instruments are used to test the focused ion beam-fabricated microtools and to develop machining procedures. This includes a Boston Digital mill having $1.0 \mu \mathrm{m}$ resolution in the plane of the workpiece ( $\mathrm{x}$ and $\mathrm{y}$ ) and $0.5 \mu \mathrm{m}$ depth resolution. With this apparatus tools are held in a collet. The combination of tool form error and spindle motion radial error is measured to be $2 \mu \mathrm{m}$ or less; this is probed approximately $2 \mathrm{~mm}$ from the end of the mandrel closest to the tool shank. In addition, microtools are tested using a modified National Jet $7 \mathrm{M}$ instrument ${ }^{8}$. It has a $1500 \mathrm{~kg}$ granite machine base for vibrational and thermal stability and all axes have air bearings. The $\mathrm{x}$ and $\mathrm{y}$ motions of the work table employ laser interferometry with a commanded resolution of $1.25 \mathrm{~nm}$, and the $\mathrm{z}$ motion has linear encoder positional control with a resolution of $20 \mathrm{~nm}$ and a vertical travel range of $150 \mathrm{~mm}$. The micromilling head consists of a specially designed v-block bearing arrangement having four spherically convex diamonds. Tools rotate about an axis dictated by the contact positions of the four diamond surfaces resulting in a cumulative radial error less than 1 $\mu \mathrm{m}$. The small error is mostly due to the variations in tool mandrel surface roughness. One tool rotation direction (clockwise looking down on a workpiece) is used for all micromilling experiments. Ultra-precision machining tests on metals involve spindle speeds of 10,000 or $18,000 \mathrm{rpm}$, fixed feed rates of $2-50 \mathrm{~mm} /$ minute, and an axial depth per pass of 0.5 or $1.0 \mu \mathrm{m}$. New data on machining PMMA at rotation speeds to 
$20,000 \mathrm{rpm}$ and depths/pass of 2.5 and $5.0 \mu \mathrm{m}$ are also included. All micromachining tests involve lubricants unless specified, and milling operations are monitored with an optical microscope and CCD camera. After machining workpieces are cleaned with isopropyl alcohol.

Scanning electron microscopy (SEM) and optical interferometry are used to analyze microtools and machined workpieces. A calibrated JEOL $6300 \mathrm{~V}$ scanning electron microscope is used to measure tool diameter, tool edge radius of curvature, trench widths and taper angles. A WYKO roughness step tester (RST) determines the roughness of starting surfaces and of machined trenches. A number of regions within the bottom of each micromachined trench are probed to obtain an accurate estimate of surface roughness.

\section{Tool fabrication}

A micro-end mill is made from a polished tool blank by ion sputtering a number of nonplanar facets as shown in Figure 1. The end of a blank is first bombarded to remove approximately $5 \mu \mathrm{m}$ from the $90 \mu \mathrm{m}$ long, $\sim 25 \mu \mathrm{m}$ diameter cylinder. This creates a smooth, polished facet with a normal direction intentionally oriented $7^{\circ}$ with respect to the tool axis in order to provide clearance for chip removal during mechanical milling. After modifying the tool end, the ion beam is deflected over areas approximately $3 \mu \mathrm{m}$ by $75 \mu \mathrm{m}$ to create chipcutting facets. With the FIB stage fixed, the gallium beam impinges normal to a plane containing the cylinder axis, but tangential to the tool shank circumference. This ion-solid geometry is chosen, because it produces one extremely sharp edge per facet.(See Figure 1) The sputtered facet edge closest to the ion source is rounded having a radius of curvature, $R_{c}$, on the order of $1.0 \mu \mathrm{m}$. This rounding is due to the part of the Gaussian beam intensity that extends outside the pattern boundary. However, continued ion beam sputtering with this particular geometry makes a sharp edge, $R_{c}<0.1 \mu \mathrm{m}$, on the facet side furthest from the ion source. A sharp edge is produced, because the ion beam has a truncated intensity distribution due to shadowing by the tool facet.

In previous publications ${ }^{9,10}$ the sharper facet edges are referred to as cutting edges, and a clear SEM image of sub-micron radius of curvature is evident in reference 10 , figure 2.

Numerous facets and sharp facet edges can be formed by rotating a tool between ion sputter steps. The number and position of facets on a micro-end mill uniquely determine a tool's properties such as clearance for removing a chip and tool rotation direction for ultra-precision machining. Figure 2 shows micro-end mills having 2, 4 and 6 cutting facets made by focused ion beam sputtering. The tool in Figure 2.a. has two cutting facets and two diagonally opposed sharp edges. However, this micro-end mill has no clearance behind facet edges, and it is likely that a significant portion of this tool burnishes a workpiece. On the other hand, the microtool shown in Figure 2.c. has six cutting facets and five sharp edges. This tool has clearance. behind each cutting edge, since almost the entire circumference is sputtered. In this study six-facet end mill tools are made with 4,5 or 6 sharp edges by selecting a particular stage rotation sequence. Furthermore, the placement of facets by FIB sputtering determines tool rotation direction for milling operations. A micro-end mill can be made so that sharp facet edges cut while rotating the tool clockwise or counter-clockwise. It is also possible to make a tool which cuts (with sharp facet edges) in both rotation directions. When using FIB sputtering to 
fabricate microtools, it is important to note that each facet forms an angle of $\sim 5^{\circ}$ with respect to the ion beam direction. This occurs because of minimal sputter yield at incidence angles greater than $80^{\circ}$ with respect to the surface normal. ${ }^{10}$ Ions impinging on a surface at near-glancing angles most often reflect without displacing atoms from lattice sites. Nevertheless, proper rotation of a tool using the sample stage compensates for this sputter-induced angle as desired.

Microtools are fabricated in 2-3 hours depending on micro-end mill design and tool material. In general, a tool having a large number of facets is fabricated in a relatively short time, because less material is removed. For example, the time required to make the six-facet tool shown in Figure 2.c. is less than the time needed for the other tools shown. Also, the fabrication time depends on tool material, since sputter rate is a function of the target mass. The sputter rate for M42 high-speed steel is known from previous studies ${ }^{6}$ to be $0.5 \mu \mathrm{m}^{3} / \mathrm{second}$. In the present work, the sputter rate for tungsten carbide is quantified by bornbarding polished wafers of identical C2-grade material with a fixed gallium dose equal to $1.0 \times 10^{19}$ ions $/ \mathrm{cm}^{2}$ ( $\mathrm{i}=2.8 \mathrm{nAmps}$ ) at $20 \mathrm{keV}$. Areas $20 \mu \mathrm{m} \times 20 \mu \mathrm{m}$ are sputtered to a small depth in order to avoid re-deposition, using a $72 \mu \mathrm{sec}$ pixel dwell time, a $0.19 \mu \mathrm{m}$ pixel spacing and a $0.86 \mathrm{sec}$ refresh time. Afterwards, a portion of the feature is crosssectioned with the gallium beam, and the depth is measured away from the feature boundary. Using the sputtered volume, an average rate of removal is calculated for $\mathrm{C} 2$ carbide equal to $0.76 \mu \mathrm{m}^{3} / \mathrm{sec}$. Significant increases in removal rate may result from ion beam bombardment in the presence of a suitable assist gas, commonly referred to as chemically enhanced etching. ${ }^{2,11.12}$ In separate experiments ${ }^{13}$, exposure to a $\mathrm{XeF}_{2}$ pressure of $7.6 \times 10^{-6}$ Torr (1.3 Torr in the gas feed line) during ion bombardment results in a 2-fold increase in material removal rate compared with ion bombardment and no gas assist.

\section{Micromilling Applications}

Initial tests of FIB fabricated micro-end mills involve machining various materials at a low feed rate of 2$3 \mathrm{~mm} /$ minute. For these experiments, as for all tests described herein, an axial depth greater than or equal to 0.5 $\mu \mathrm{m}$ is milled per pass. These depths are chosen, because a microtool 'appears' sharp when compared to the cutting action, i.e., the tool edge $R_{c}$ is less than the thickness removed. Also, for these initial tests, microtools are rotated so that sharp facet edges cut the workpiece. Initially we avoid rotation that results in cutting with the rounded edges, since a dull tool normally results in very high cutting forces. Incorrect rotation is deliberately attempted in the latter part of the study, simply to observe the consequences.

FIB fabricated microtools successfully machine trenches in PMMA, 6061-T4 aluminum, brass and 4340 steel at low feed rates ${ }^{14}$. For all tests except for one, 15-25 $\mu \mathrm{m}$ deep trenches are cut several millimeters in length as commanded. As summarized in Table 1, the surface roughness (rms) of trenches machined at low feed rates is small, $\sim 150$ nanometers or less. These values are averages taken from several areas within a given trench and account for both transverse and longitudinal milling directions. In addition, all trenches milled in PMMA, Al alloy and 4340 steel have nearly vertical sidewalls. SEM shows a slight taper of $\sim 1-2^{\circ}$ from 
vertical. Near-vertical sidewalls are present on both sides of micromachined trenches; this is demonstrated in $6061 \mathrm{Al}$ (Figure 3) and 4340 steel (Figure 4).

SEM shows that micromachined trench widths are nominally the same as the tool diameters. Experiments with the Boston Digital apparatus produce trench widths that are $\sim 2 \mu \mathrm{m}$ larger than the tool diameters. This small deviation is attributed to the radial error motion of the spindle. Additional milling tests with the modified National Jet apparatus at large axial depths of cut and rotation speeds to $20,000 \mathrm{rpm}$ produces similar results (see tests highlighted in bold, Table 1). Trenches milled in PMMA are limited at $2 \mu \mathrm{m}$ larger than the tool diameter, and the trench width does not vary with increasing depth of cut. With the National Jet instrument, a tool is held in a v-block bearing assembly that is specially designed to minimize radial error beyond the variations in surface roughness of the tool mandrel. ${ }^{6}$ Therefore, we expect that the difference between the micro-end mill diameter and the trench width results from the size of PMMA chips and tool vibration. Nevertheless, tests with both milling instruments produce trench widths that are uniform over several millimeters. For example, Figure 5 shows a trench milled in brass having a total length of $10 \mathrm{~mm}$ and a uniform width of $28.8 \mu \mathrm{m}$ (measured at half depth). This feature requires 25 passes for completion and demonstrates the positioning repeatability of high precision milling systems. Interestingly, the experiments listed in Table 1 show a single test that results in a significantly larger trench width and surface roughness. Machining 6061 aluminum without a lubricant gives a trench width $\sim 6 \mu \mathrm{m}$ larger than the tool diameter, and the roughness of the trench is $550 \mathrm{~nm}$. This ultra-precision machining test results in microtool fracture, with breakage occuring during the twelfth pass.

From the experiments at low feed rates, there are several indications that microtools cut chips during ultraprecision machining. While milling PMMA and $6061 \mathrm{Al}$ without a lubricant for brief amounts of time, small chips are continuously ejected from the vicinity of a moving tool. Evidence of cutting is also demonstrated with micrographs of workpieces taken after machining but prior to cleaning. For example, Figure 6 shows the terminal section of four parallel grooves milled in PMMA at 20,000 rpm with 2.5 and $5.0 \mu \mathrm{m}$ axial depths per cut. The curled piece of debris near the base of groove $\# 2$ indicates that PMMA is removed by cutting chips. Furthermore, tool-cutting marks characterize the bottom of machined trenches, as shown in Figure 3.c. Cutting marks are evident in all trenches fabricated in $\mathrm{Al}$ alloy, brass, PMMA and 4340 steel.

Additional ultra-precision machining experiments probe microtool performance for increased chip load rates. These milling tests involve constant feed rates of $3,10,25$ and $50 \mathrm{~mm} / \mathrm{minute}$, and again a tool is rotated so that sharp facet edges cut a workpiece. For each table feed rate, a single two-facet microtool successfully mills $25 \mu \mathrm{m}$ deep, $7 \mathrm{~mm}$ long trenches in 6061-T4 Al. As described in the first part of Table 2, the micromilled trench widths are approximately the same size as the tool diameter, $21.7 \mu \mathrm{m}$, independent of feed rate. In addition, the surface roughnesses (rms) measured in the bottom of milled trenches are $\sim 160 \mathrm{~nm}$ or less. These measurements show that FIB-fabricated microtools mill metal alloys at fairly high rates without significant tool dulling. Similar trench widths and roughnesses are observed for increased feed rates. Again the sidewalls of micromachined trenches are nearly vertical. Furthermore, micro-end mills are robust despite their small size 
and 'apparent' delicate nature. The two-facet microtool, labeled B3, milled $6061 \mathrm{Al}$ for over 6 hours without tool fracture.

For all experiments described in Table 1 and in the first half of Table 2, tools are rotated clockwise such that the sharper facet edges cut workpieces. Additional experiments investigate the influence of cutting edge radius of curvature on tool performance and feature definition. In order to probe this relationship, a microtool is made so that rounded facet edges contact the workpiece for a clockwise tool rotation. This is accomplished by ion sputtering four facets of similar size onto a polished tool blank. However, facets are ion milled on the opposite side of the tool shank axis, compared with the procedure shown in Figure 1. As summarized in the second half of Table 2, this four-facet microtool, rotating at 18,000 rpm (clockwise), mills $25 \mu \mathrm{m}$ deep, $7 \mathrm{~mm}$ long trenches at the feed rates listed. In each case, the microtool mills aluminum alloy without breaking. Tool cutting marks again characterize the bottom of all trenches and surface roughnesses are $-250 \mathrm{~nm}$ or less, verifying that a cutting edge radius of curvature closer to $1 \mu \mathrm{m}$ is sufficiently sharp for milling $\mathrm{Al}$ alloy when choosing a $0.5 \mu \mathrm{m}$ depth per pass. However, a closer look at the data in Table 2 reveals that the trench widths are considerably larger than the tool diameter. On average the feature size is $6 \mu \mathrm{m}$ larger than the microtool diameter, $24.0 \mu \mathrm{m}$. These results are significant and demonstrate that the FIB sputtering procedure for making sharp cutting edges is critical for accurately controlling feature size. It is expected that sharp facet edges produced by ion sputtering reduce cutting forces and prevent deformation /fracture of the microtool.

In conclusion, this work demonstrates a technique for fabricating a diverse set of materials at the microscale. Sharp micro-end mill tools made by focused ion beam sputtering fabricate different metal alloys with control over $25 \mu \mathrm{m}$ feature sizes. Placement of facets and a proper stage rotation sequence during focused ion beam sputtering is critical for accurately controlling feature size during ultra-precision machining. The technique used for making micro-end mills allows for various tool designs and is capable of fabricating smaller tools. FIB sputtering is useful for making other types of micro-cutting tools and is not limited to micro-end mills. For example, high-precision threading and grooving tools for lathe machining of nonplanar substrates are possible. In the immediate future, FIB sputter fabrication of microtools will involve formation of a number of facets but not complex geometries such as spiral flutes. Although this remains a difficult task complicated by the sputter yield dependence on incidence angle, recent progress has been made toward 'three-dimensional' micromachining via focused ion beam sputtering. ${ }^{15}$

\section{Acknowledgements}

The authors thank M.B. Ritchey (SNL) for SEM work, H. Apodaca (SNL) and A. Gunasekaran (LTU). Also, the efforts of A.A. Pimentel are appreciated for preliminary experiments involving $\mathrm{XeF}_{2}$ exposure. MJV acknowledges support from the Louisiana Board of Regents. Part of this work was performed at Sandia National Laboratories and is supported by the United States Department of Energy under Contract No. DE-AC04-94AL85000. Sandia is a multiprogram laboratory operated by Sandia Corporation, a Lockheed Martin Company, for the United States Department of Energy. 


\section{References}

1 For a review of alternative microfabrication techniques, see G. Thornell and S. Johansson, "Microprocessing at the Fingertips," J. Micromech. Microeng., vol. 8, pp. 251-262, 1998.

2 J. Orloff, "High-resolution focused ion beams," Rev. Sci. Instrum. vol. 64, pp. 1105-1130, 1993.

3 T. Ishitani, T. Ohnishi and Y. Kawanami, "Micromachining and Device Transplantation Using Focused Ion Beam," Jap. J. Appl. Phys., vol. 29, pp. 2283-2287, 1990.

4 M.J. Vasile, C.J. Biddick and S.A. Schwalm, "Microfabrication by ion milling: The lathe technique," $J$. Vac. Sci. Technol. B, vol. 12, p. 2388, 1994.

5 P.E. Russell, T.J. Stark, D.P. Griffis, J.R. Phillips and K.F. Jarausch, "Chemically and Geometrically Enhanced Focused Ion-Beam Micromachining," J. Vac. Sci. Technol. B, vol. 16, pp. 2494-2498, 1998.

6 M.J. Vasile, C.R. Friedrich, B. Kikkeri, and R. McElhannon, "Micrometer-scale machining: tool fabrication and initial results," J. of Precision Engineering, vol. 19, no. 2/3, pp. 180-186, 1996. C.R. Friedrich and M.J. Vasile, "Development of the micromilling process for high aspect ratio microstructures," J. Microelectromech. Sys., vol. 5, p. 33, 1996.

7 L.R. Harriott, "A second generation focused ion beam micromachining system," Proc. SPIE, vol. 773, p. 190, 1987.

8 This apparatus was a joint project among Louisiana Tech University (IfM), the National Jet Company and . Dover Instruments.

9 D.P. Adams, G. Benavides and M.J. Vasile, "Micrometer-scale machining of metals and polymers enabled by focused ion beam sputtering," Mat. Res. Soc. Proc., vol. 546, pp. 201-206, 1999.

10 M.J.Vasile, R.Nassar, J.Xie, and H. Guo, "Microfabrication techniques using focused ion beams and emergent applications," Micron, vol. 30, pp. 235-244, 1999.

11 Y. Ochiai, K. Gamo and S. Namba, "Pressure and Irradiation angle Dependence of Maskless Ion-Beam Assisted Etching of GaAs and Si," J. Vac. Sci. Technol. B, vol. 3, pp. 67-70, 1985.

12 T.J. Stark, G.M. Shedd, J. Vitarelli, D.P. Griffis and P.E. Russell, " $\mathrm{H}_{2} \mathrm{O}$ Enhanced Focused Ion-Beam Micromachining," J. Vac. Sci. Technol. B, vol. 13, 2585 (1995).

13 These separate experiments involve a Micrion FIB system, using ion energies of $30 \mathrm{keV}$ (with and without $\mathrm{XeF}_{2}$ exposure). Pixel spacing $=0.010 \mu \mathrm{m}$; pixel dwell time $=10 \mu \mathrm{sec}$.

14 Hardness values for the different workpiece materials include 6061-T4 aluminum, Rockwell $\mathrm{B}=26$; brass, Rockwell $\mathrm{B}=35$ and 4340 steel, Rockwell $\mathrm{B}=97$.

15 M.J. Vasile, R. Nassar, Z. Niu, W. Zhang and S. Liu, "Focused ion beam milling: depth control for threedimensional microfabrication," J. Vac. Sci. Technol. B, vol. 15, $2350,1997$. 
Table 1:

\begin{tabular}{|c|c|c|c|c|c|c|c|c|}
\hline $\begin{array}{c}\text { Tool\#, \#Cutting edges, } \\
\text { Tool Material }\end{array}$ & $\begin{array}{c}\text { Tool } \\
\text { Diameter } \\
(\mu \mathrm{m})\end{array}$ & $\begin{array}{c}\text { Workpiece } \\
\text { Material }\end{array}$ & $\begin{array}{c}\text { Workpiece } \\
\text { Surface Finish, } \\
\mathrm{R}_{\mathrm{ms}}, \mathrm{R}_{\mathrm{a}}(\mathrm{nm})\end{array}$ & $\begin{array}{c}\text { Rotation } \\
\text { Speed, } \\
(\mathrm{rpm})\end{array}$ & $\begin{array}{c}\text { Feed } \\
\text { Rate, } \\
(\mathrm{mm} / \mathrm{min})\end{array}$ & $\begin{array}{c}\text { Depth } \\
\text { Per pass, } \\
(\mu \mathrm{m})\end{array}$ & $\begin{array}{c}\text { Trench } \\
\text { Width, } \\
(\mu \mathrm{m})\end{array}$ & $\begin{array}{c}\text { Roughness, } \\
\text { Trench Bottom } \\
\mathrm{R}_{\mathrm{ms}}, \mathrm{R}_{\mathrm{a}}(\mathrm{nm})\end{array}$ \\
\hline Q2, 4, HSS & 24.0 & PMMA & 58,50 & 18,000 & 2.0 & 0.5 & 26.2 & 122,93 \\
\hline Q11, 4 HSS & $\mathbf{2 8 . 0}$ & PMMA & NA & $\mathbf{1 8 , 0 0 0}$ & $\mathbf{2 . 0}$ & $\mathbf{2 . 5}$ & $\mathbf{3 0 . 5}$ & NA \\
\hline Q11, 4 HSS & $\mathbf{2 8 . 0}$ & PMMA & NA & $\mathbf{2 0 , 0 0 0}$ & $\mathbf{2 . 0}$ & $\mathbf{2 . 5}$ & $\mathbf{3 0 . 2}$ & NA \\
\hline Q11, 4 HSS & $\mathbf{2 8 . 0}$ & PMMA & NA & $\mathbf{2 0 , 0 0 0}$ & $\mathbf{2 . 0}$ & $\mathbf{5 . 0}$ & $\mathbf{2 9 . 0}$ & NA \\
\hline H4, 4, HSS & 26.2 & Al 6061-T4 & 460,370 & 10,000 & 2.0 & 1.0 & 28.2 & 126,92 \\
\hline B2, 2, HSS & 23.6 & Al 6061-T4 & 155,130 & 18,000 & $2.0 t$ & 0.5 & 30.0 & 550,458 \\
\hline B3, 2, WC & 21.7 & Al 6061-T4 & 361,267 & 18,000 & 3.0 & 1.0 & 23.0 & 161,117 \\
\hline H6, 5, HSS & 25.0 & & & & & & & \\
\hline Q6, 4, WC & 22.5 & Brass & 430,330 & 10,000 & 2.0 & 1.0 & 28.8 & 177,139 \\
\hline
\end{tabular}

Tool \# Code: $1^{\text {st }}$ letter designates overall shape $\mathrm{H}=\mathrm{Hextool}$ ( 6 facets); $\mathrm{B}=$ Bitool (2 facets); $\mathrm{Q}=\mathrm{Quad}$ tool (4 facets)

Tool Material Code: HSS $=$ M42 Cobalt High Speed Steel; WC $=\mathrm{C} 2$ micrograin tungsten carbide

t No lubricant used during machining. Only 11 passes completed.

Table 1. Machining parameters and results from micromilling different materials at low feed rates, 2 or 3 $\mathrm{mm} /$ minute. Tools are made of high-speed steel or tungsten carbide, but have different designs. 
Table 2:

\begin{tabular}{|c|c|c|c|c|c|c|c|c|}
\hline $\begin{array}{c}\text { Tool\#, \#Cutting edges, } \\
\text { Tool Material }\end{array}$ & $\begin{array}{c}\text { Tool } \\
\text { Diameter } \\
(\mu \mathrm{m})\end{array}$ & $\begin{array}{l}\text { Workpiece } \\
\text { - Material }\end{array}$ & $\begin{array}{c}\text { Workpiece } \\
\text { Surface Finish, } \\
\mathrm{R}_{\mathrm{rms}}, \mathrm{R}_{\mathrm{a}}(\mathrm{nm})\end{array}$ & $\begin{array}{l}\text { Rotation } \\
\text { Speed, } \\
\text { (rpm) }\end{array}$ & $\begin{array}{c}\text { Feed } \\
\text { Rate, } \\
(\mathrm{mm} / \mathrm{min})\end{array}$ & $\begin{array}{l}\text { Depth } \\
\text { per pass, } \\
(\mu \mathrm{m})\end{array}$ & $\begin{array}{l}\text { Trench } \\
\text { Width, } \\
(\mu \mathrm{m})\end{array}$ & $\begin{array}{l}\text { Roughness, } \\
\text { Trench Bottom } \\
\mathrm{R}_{\mathrm{rms}}, \mathrm{R}_{\mathrm{a}}(\mathrm{nm})\end{array}$ \\
\hline B3, 2, WC & 21.7 & $\mathrm{Al}$ 6061-T4 & 361,267 & 18,000 & 3.0 & 1.0 & 23.0 & 161,117 \\
\hline B3, 2, WC & 21.7 & $\mathrm{Al}$ 6061-T4 & $361,267^{\circ}$ & 18,000 & 10.0 & 1.0 & 22.0 & 111,83 \\
\hline $\mathrm{B} 3, \quad 2, \quad \mathrm{WC}$ & 21.7 & Al 6061-T4 & 361,267 & 18,000 & 25.0 & 1.0 & 23.1 & 108,82 \\
\hline B3, $2, \quad W C$ & 21.7 & $\mathrm{Al} 6061-\mathrm{T} 4$ & 361,267 & 18,000 & 50 & 1.0 & 22.5 & 139,102 \\
\hline Q2, 4, HSS & 24.0 & $\mathrm{Al} \mathrm{6061-T4}$ & 610,560 & $18,000^{*}$ & 2.0 & 0.5 & 30.4 & 65,55 \\
\hline $\mathrm{Q} 2, \quad 4, \mathrm{HSS}$ & 24.0 & $\mathrm{Al} \mathrm{6061-T4}$ & 610,560 & $18,000^{*}$ & 5.0 & 0.5 & 30.0 & 67,49 \\
\hline Q2, 4, HSS & 24.0 & Al 6061-T4 & 610,560 & $18,000^{*}$ & 10.0 & 0.5 & 29.3 & 85,61 \\
\hline Q2, 4, HSS & 24.0 & $\mathrm{Al} \mathrm{6061-T4}$ & 610,560 & $18,000^{*}$ & 25 & 0.5 & 29.2 & 101,74 \\
\hline Q2, 4, HSS & 24.0 & Al 6061-T4 & 610,560 & $18,000^{*}$ & 50 & 0.5 & 30.0 & 237,170 \\
\hline
\end{tabular}

Tool \# Code: $1^{\text {st }}$ letter designates overall shape $\mathrm{H}=$ Hextool (6 facets); $\mathrm{B}=$ Bitool (2 facets); $\mathrm{Q}=\mathrm{Quad}$ tool (4 facets)

Tool Material Code: HSS = M42 Cobalt High Speed Steel; WC $=$ C2 micrograin tungsten carbide

* Tool was designed to cut with rounded facet edges when rotated clockwise.

Table 2. Machining parameters and results from milling Al 6061-T4 alloy at different feed rates. 


\section{Figures:}

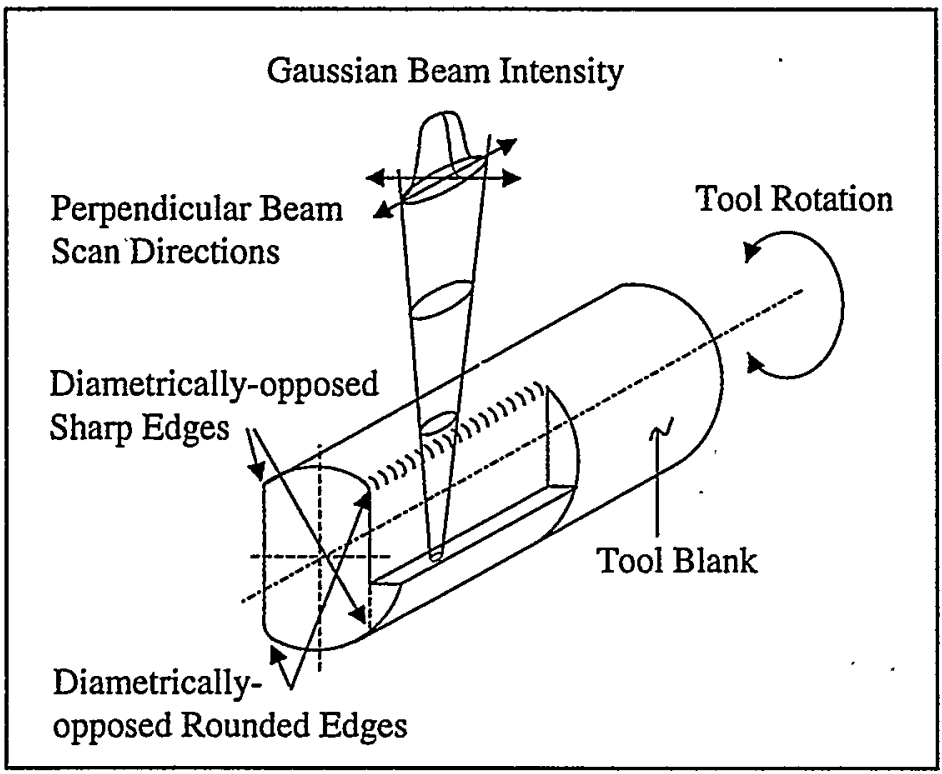

Figure 1. Micro-end mill fabrication procedure. Schematic shows tool end.
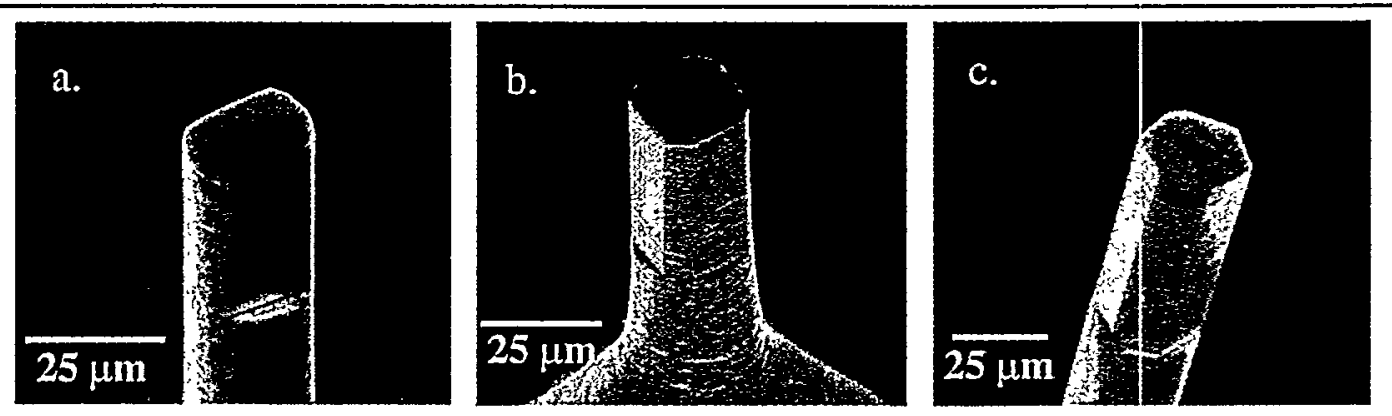

Figure 2. Micro-end mills made by focused ion beam sputtering having 2, 4 and 5 cutting edges. Scanning electron micrographs. 


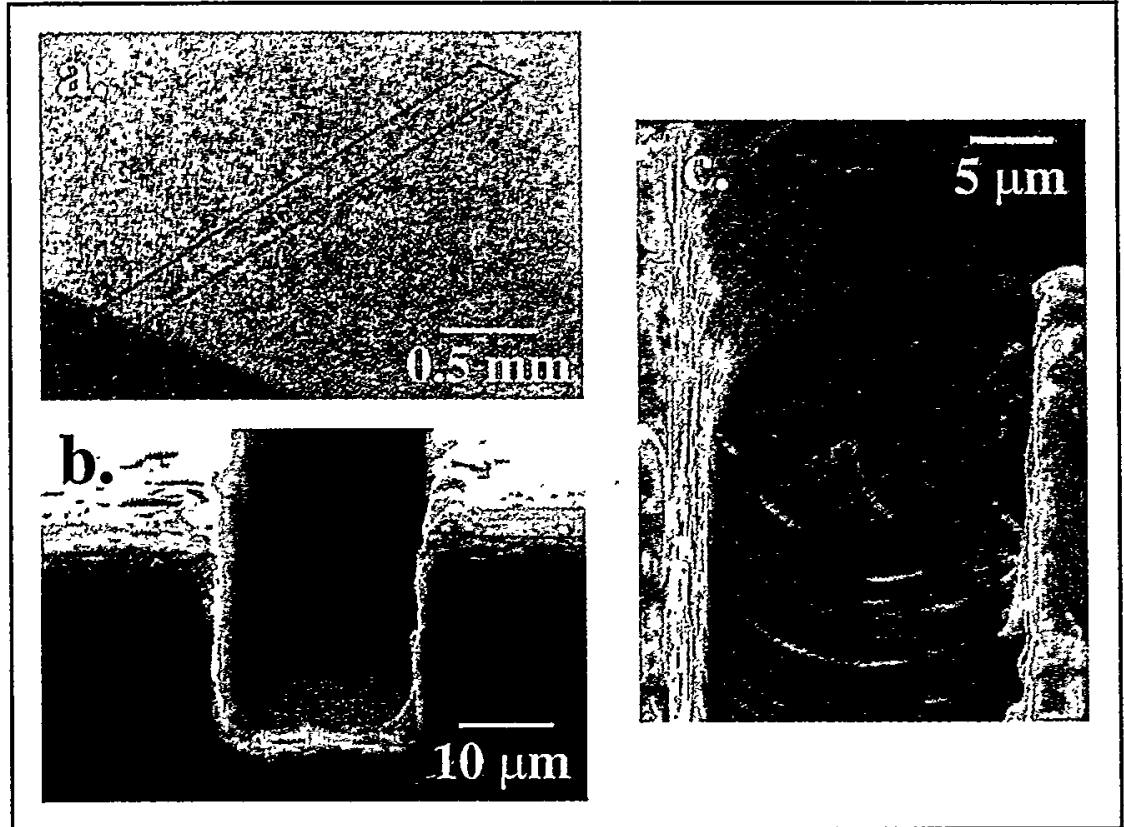

Figure 3. Al 6061 alloy machined using a 4-edge micro-end mill. Scanning electron micrographs show nearvertical sidewalls (b.) and tool cutting marks in bottom of trench (c.). Debris around trench is approximately $1 \mu \mathrm{m}$ above initial work-piece surface.

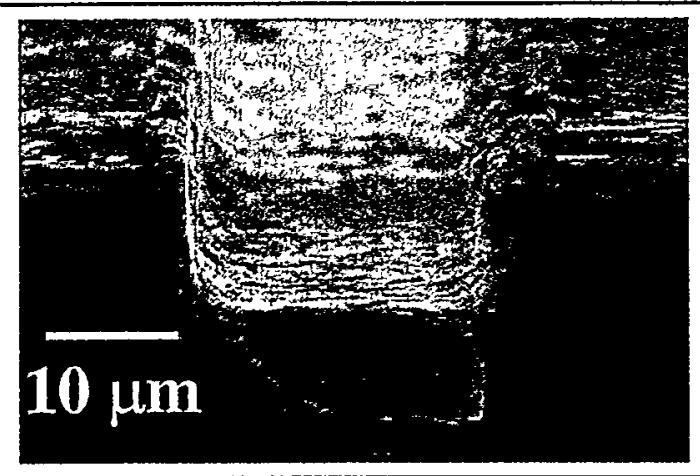

Figure 4. Scanning electron micrograph of 4340 steel machined with tungsten carbide micro-end mill. 


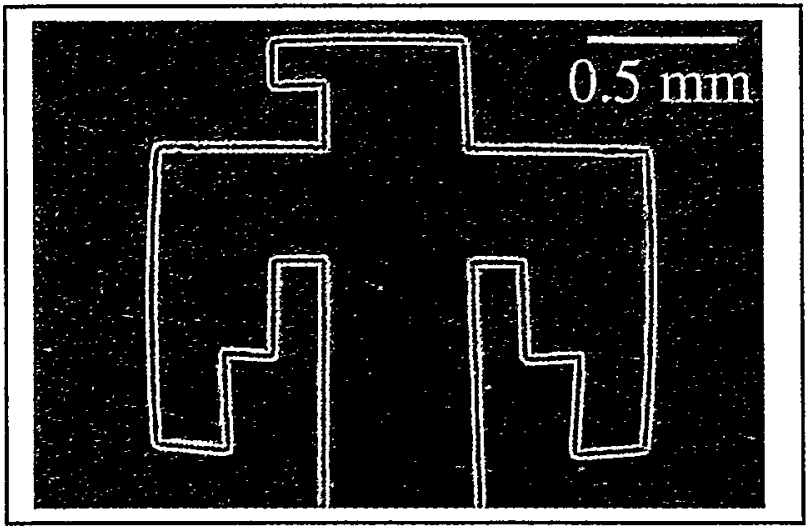

Figure 5. Brass machined with micro-end mill tool having 5 cutting edges. Plan view scanning electron micrograph.

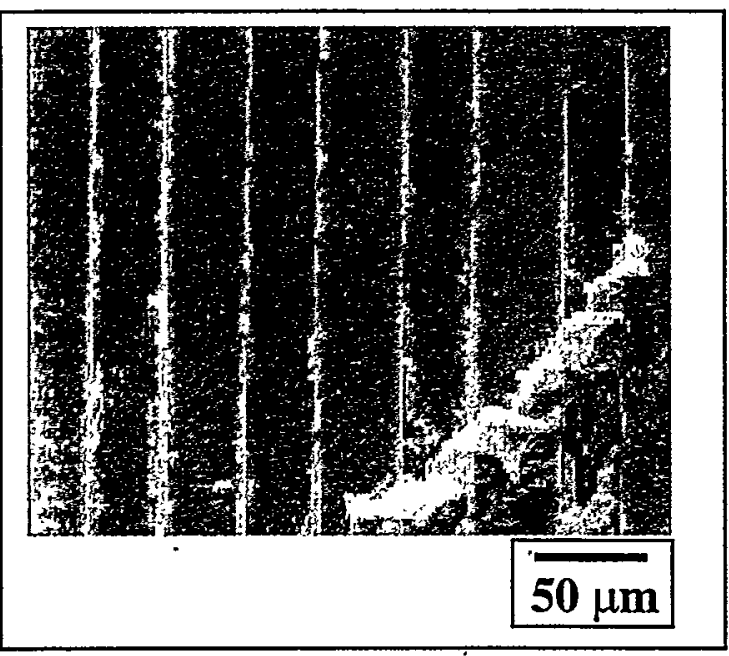

Figure 6. Four parallel grooves milled in PMMA at 20,000 RPM with $2 \mathrm{~mm} / \mathrm{min}$ feed rate. The curled chip is evidence of cutting. Micrograph is taken prior to cleaning workpiece. 